AC 2012-5043: A CELL CULTURE-BASED BIOCOMPATIBILITY MODULE FOR BIOMEDICAL ENGINEERS

Donna M. Ebenstein, Bucknell University

Donna M. Ebenstein is an Assistant Professor of biomedical engineering at Bucknell University.

Dr. Eric A. Kennedy, Bucknell University

(C)American Society for Engineering Education, 2012

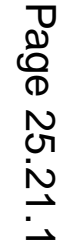




\title{
A Cell Culture-Based Biocompatibility Module for Biomedical Engineers
}

\begin{abstract}
The challenge of exposing biomedical engineering students to the broad array of core engineering and biology topics often makes it difficult to adequately address all relevant areas of the biomedical engineering field in the undergraduate curriculum. This paper will present a cellculture based biocompatibility module with laboratory and lecture components that can be easily integrated into an engineering or biomaterials course.
\end{abstract}

This module was developed to introduce students to basic cell culturing techniques and to provide students with exposure to the issues related to the interaction between living and nonliving materials (ABET Bioengineering Program Criteria). The lecture component focuses on biocompatibility issues, including: the definition of biocompatibility, cellular response to implantation of a foreign material, and the types of biocompatibility tests recommended by the FDA. For the laboratory component, students are first introduced to basic cell culture techniques, including sterile technique, cell counting, and cell splitting. Next, students perform an in vitro cytotoxicity assay (direct contact) based on ISO-10993, gaining hands-on experience in biocompatibility testing.

In its current form, the core unit consists of two hours of lecture and seven hours of cell culture lab spread over three weeks; however, this unit can be shortened or expanded depending on time available and the amount of supplementary topics introduced. A stand-alone cytotoxicity assay, for example, could be completed by students in one week. Examples of supplemental activities that can be incorporated into the unit are included below:

- Expanded group and individual cell culturing: After students learn and practice sterile technique and cell culturing principles within small groups, each student is responsible to split and maintain their own cell line for a period of time.

- Training videos: To reinforce proper cell culturing practices, groups of students generate training videos to demonstrate procedures such as good and bad pipetting practices, performing a cell split, or counting cells.

- Standards: The use of the ISO-10993 cytotoxicity assay opens the door for instruction on the role of standards documents in defining accepted test procedures for medical device development, and introduces the topic of standards organizations as a whole.

- Statistics: Statistical methods can be reinforced by involving students in the design of the experiments and requiring statistical analysis of quantifiable results of the cell culture experiments, such as image analysis of the size and shape of cells or cell counts.

- Bioethics: The use of HeLa cells or other cell lines originating from traceable human donors affords an opportunity to discuss bioethics issues relating to biologic specimen collection.

The self-contained biocompatibility module described in this paper provides biomedical engineering students with relevant cell culture experience and exposure to the interactions between living and non-living materials. A simple biocompatibility lecture-lab module can be incorporated into an existing class as a one or two week unit, or the length and depth of the unit can be expanded through the incorporation of optional supplemental activities. Assessment results from the past three years demonstrate that the module enables students to meet biocompatibility-related performance criterion, and student satisfaction is indicated by positive comments from student course evaluations. 


\section{Introduction}

The challenge of exposing biomedical engineering students to the broad array of core engineering and biology topics often makes it difficult to adequately address all relevant areas of the biomedical engineering field in the undergraduate curriculum. This paper will present a cellculture based biocompatibility module with laboratory and lecture components that can be easily integrated into an engineering or biomaterials course.

Within the biomedical engineering curriculum at Bucknell University, a senior-level fabrication and experimental design course is integrated into a four course design sequence where two courses comprise the senior capstone experience and two courses teach supplementary material. The intent of the sequence is to provide experience with a variety of skills that are valuable for both senior design projects and in BME careers after graduation. As designed, the Fabrication and Experimental Design course is not a full-credit course, meeting only two days a week for one-hour sessions, with several lab sessions (approximately 2 hours long) scheduled outside of normal classroom hours. Half of the course is devoted to the use of CAD software, an introduction to rapid prototyping machines and a hands-on introduction to the machining tools of the College of Engineering's machine shop. The other half of the semester is devoted to cell culturing and biostatistics.

This module was developed to introduce students to basic cell culturing techniques and to provide students with exposure to the issues related to the interaction between living and nonliving materials (ABET Bioengineering Program Criteria). The lecture component focuses on biocompatibility issues, including: the definition of biocompatibility, cellular response to implantation of a foreign material, and the types of biocompatibility tests recommended by the FDA. For the laboratory component, students are first introduced to basic cell culture techniques, including sterile technique, cell counting, and cell splitting. Next, students perform an in vitro cytotoxicity assay (direct contact) based on ISO-10993, gaining hands-on experience in biocompatibility testing.

Given the structure of the course, there were many challenges in implementing an effective cell culture unit. For example, meeting only two hours a week for a half semester provided limited time to cover both cell culture and statistics and it was difficult to convince students of the relevance of cell culture to the course and their future careers. In attempting to meet the goals of providing a biomedically-relevant cell culture experience to biomedical engineers in a short time, the cell culture unit has evolved substantially since the course was introduced in fall 2006.

For the 2006 and 2007 course offerings, the cell culture unit consisted of training in sterile technique and cell culture followed by a growth curve experiment comparing normal and cancer cells. These were time intensive experiments (growth curves require data collection several times a day) requiring extensive lab time outside of class. In course evaluations those years, students complained about the time spent in lab to perform cell culture and they did not consider the cell culture experiments a valuable part of the course.

To address these concerns, beginning in fall 2008, a more biomedically relevant experiment was incorporated into the class. Rather than focusing on cell growth, a cell cytotoxicity experiment was developed based on appropriate ISO and ASTM standards (1-5). This experiment was 
motivated by lectures on biocompatibility and relevant biocompatibility tests for different medical devices, illustrating that cell cytotoxicity tests are required for all body-contacting medical devices $(1,6)$. At the same time, the amount of time required in lab both in and outside of class was reduced to reflect the fact that the course was not a full credit course. Following these changes, students commented positively on the cell culture experience, sometimes requesting that more time in the class be devoted to that unit.

While developing this unit (lecture plus lab), consideration was also given to satisfying ABET criterion. Specifically, we wanted to introduce students to the use of standards and use this unit to provide students with exposure to the interaction between living and non-living systems, as specified by the ABET Bioengineering Program Criteria (7): "The program must demonstrate that graduates have... the ability to make measurements on and interpret data from living systems, addressing the problems associated with the interaction between living and non-living materials and systems."

In this paper, we will provide a detailed description of a three week core module which can be completed in two lecture hours and seven lab hours in addition to brief descriptions of supplemental activities that can be used to expand the unit, including biostatistics and ethics. For the core module and each supplemental activity, the time and materials resources required will be indicated, as well as the ABET criterion that are addressed. Finally, we will report on ABET and student assessment relating to the unit, and end with some discussion and conclusions.

\section{Core Module}

The core module consists of two hours of lecture and seven hours of lab. In our course, this covers three weeks of class - one week of lecture followed by two weeks of lab; however, supplemental activities used during our unit extend our current offering to four and a half weeks of class. One homework assignment and one lab report are the deliverables of the core unit, and serve as the basis for ABET assessment. Supplementary activities are not directly assessed.

\section{Lectures}

The lecture covers topics related to biocompatibility. The first lecture focuses on defining biocompatibility, cellular responses to implantation of a foreign material, and non-biocompatible (e.g., granuloma, chronic inflammation) and application-specific biocompatible (e.g., treat like native tissue, break down and replace with native tissue, tissue adhesion or ingrowth, stable fibrous capsule) outcomes of device implantation. The functional definition of biocompatibility provided to the class is: "Biocompatibility is the ability of a material to perform with an appropriate host response in a specific application." The emphasis is placed on the idea that biocompatibility is application-specific, and students are asked to interpret whether a particular body response would be considered biocompatible for a specific implant type. It is also emphasized that there is no list of "biocompatible materials" published by the FDA because materials have to be independently shown to be biocompatible for a specific application. Slides for this lecture were largely adapted from slides that accompanied the text: "Biomaterials, Artificial Organs and Tissue Engineering” (8). Other valuable sources for lecture material on biocompatibility include "Biomaterials Science: An Introduction to Materials in Medicine" (9) and "Biomaterials: The Intersection of Biology and Materials Science" (10). 
The second lecture focuses on the types of biocompatibility tests recommended by the FDA for different applications (6). A table of recommended tests posted on the FDA website (which is adapted from "ISO 10993-1: Biological evaluation of medical devices - Part 1") is used as the basis for this lecture (Table 1). The standard provides explanations of each type of test, and examples of how to interpret "nature of body contact" and "contact duration" (1). The Medical Device and Diagnostic Industry (MDDI) website provide easy-access information on how to test for each of the biological effects (11). The emphasis of this lecture is on learning to identify the FDA-recommended biocompatibility tests for a specific medical application or device using Table 1 . This table is also used to motivate the biomedical relevance of the cell cytotoxicity assay - notice that cytotoxicity tests are required for all body-contacting medical devices, even devices that only contact the skin for less than 24 hours.

\section{Laboratory Exercises}

The core laboratory unit consists of five parts. The first two parts are introduction to sterile technique and cell splitting, while the last three parts together comprise the cell cytotoxicity assay. Specifically, a direct contact in vitro cell cytotoxicity assay was performed. This means that material specimens were placed directly on top of plated cells (Figure 1), rather than using a material extract or indirect contact test (where an agar layer is placed between the cells and the material). This experimental protocol was based on the following standards:

- Overview of types of biocompatibility tests (1-2):

- $\quad$ ISO 10993-1: Biological evaluation of medical devices - Part 1: Evaluation and testing

- $\quad$ ASTM F748-04: Standard practice for selecting generic biological test methods for materials and devices

- Overview of three types of in vitro cell cytotoxicity assays (extract, direct-contact, indirect contact (agar diffusion)) (3-5):

- $\quad$ ISO 10993-5: Biological evaluation of medical devices - Part 5: Tests for in vitro cytotoxicity

- $\quad$ ISO 10993-12: Biological evaluation of medical devices - Part 12: Sample preparation and reference materials

- $\quad$ ASTM F813-01: Standard practice for direct contact cell culture evaluation of materials for medical devices

The general procedure for the direct contact in vitro cell cytotoxicity assay is to place materials gently on top of a subconfluent ( 70-90\% confluent) cell layer (Figure 1). Experiments are performed in triplicate, with the following controls:

- Untreated control (no material placed on cells)

- Negative control (non-cytotoxic material, we used high density polyethylene (HDPE))

- Positive control (cytotoxic material, we used copper)

The size of the material specimens should cover only $10 \%$ of the surface area. Cell response is observed 24 hours after material placement. ISO 10993-5 recommends qualitative assessment using a 0-3 scale (Table 2). Evidence of cytotoxicity includes cells balling up and detaching from the flask surface, and a decrease in cell density (Figure 2). Notice that the cells from the positive control (copper) flask are rounder in appearance and have a lower cell density than the other three flasks, which exhibit non-cytotoxic responses. In the untreated, negative control, and test material flasks, cells are spread and cover almost the entire flask surface. 
Table 1: Initial evaluation tests for consideration in biocompatibility testing, taken directly from US Food and Drug Administration guidance documents (6).

\begin{tabular}{|c|c|c|c|c|c|c|c|c|c|c|}
\hline \multicolumn{3}{|c|}{ Medical de vice categorization by } & \multicolumn{8}{|c|}{ Biological effect } \\
\hline $\begin{array}{r}\text { Nature of b } \\
\text { (se }\end{array}$ & $\begin{array}{l}\text { dy contact } \\
4.2) \\
\text { Contact }\end{array}$ & $\begin{array}{c}\begin{array}{c}\text { Contact duration } \\
\text { (see 4.3) }\end{array} \\
\begin{array}{c}\text { A - Limited } \\
(<24 \mathrm{~h})\end{array} \\
\text { B - Prolonged } \\
\text { (24 h to } 30 \text { days) } \\
\text { C - Permanent } \\
\text { (>30 days) }\end{array}$ & 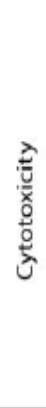 & 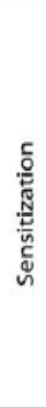 & 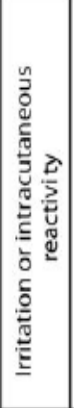 & 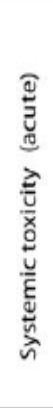 & 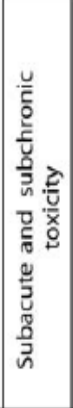 & 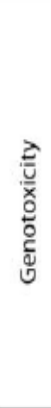 & 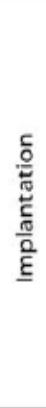 & 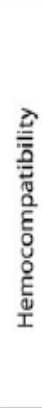 \\
\hline \multirow{9}{*}{ Surface device } & \multirow{3}{*}{ Skin } & A & $x$ & $x$ & $x$ & & & & & \\
\hline & & $B$ & $x$ & $x$ & $x$ & & & & & \\
\hline & & $\mathrm{C}$ & $x$ & $x$ & $x$ & & & & & \\
\hline & \multirow{3}{*}{$\begin{array}{l}\text { Mucosal } \\
\text { membrane }\end{array}$} & A & $x$ & $x$ & $x$ & & & & & \\
\hline & & B & $x$ & $x$ & $x$ & & & & & \\
\hline & & $\mathrm{C}$ & $x$ & $x$ & $x$ & & $x$ & $x$ & & \\
\hline & \multirow{3}{*}{$\begin{array}{l}\text { Breached or } \\
\text { compromised } \\
\text { surface }\end{array}$} & A & $x$ & $x$ & $x$ & & & & & \\
\hline & & $B$ & $x$ & $x$ & $x$ & & & & & \\
\hline & & $\mathrm{C}$ & $x$ & $x$ & $x$ & & $x$ & $x$ & & \\
\hline \multirow{9}{*}{$\begin{array}{c}\text { External } \\
\text { communicating } \\
\text { device }\end{array}$} & \multirow{3}{*}{$\begin{array}{l}\text { Blood path, } \\
\text { indirect }\end{array}$} & A & $x$ & $x$ & $x$ & $x$ & & & & $x$ \\
\hline & & B & $x$ & $x$ & $x$ & $x$ & & & & $x$ \\
\hline & & $\mathrm{C}$ & $x$ & $x$ & & $x$ & $x$ & $x$ & & $x$ \\
\hline & \multirow{3}{*}{ Tissue/bone/dentin } & A & $x$ & $x$ & $x$ & & & & & \\
\hline & & B & $x$ & $x$ & $x$ & $x$ & $x$ & $x$ & $x$ & \\
\hline & & $\mathrm{C}$ & $x$ & $x$ & $x$ & $x$ & $x$ & $x$ & $x$ & \\
\hline & \multirow{3}{*}{ Circulating blood } & A & $x$ & $x$ & $x$ & $x$ & & & & $x$ \\
\hline & & $B$ & $x$ & $x$ & $x$ & $x$ & $x$ & $x$ & $x$ & $x$ \\
\hline & & $C$ & $x$ & $x$ & $x$ & $x$ & $x$ & $x$ & $x$ & $x$ \\
\hline \multirow{6}{*}{ Implant device } & \multirow{3}{*}{ Tissue/bone } & A & $x$ & $x$ & $x$ & & & & & \\
\hline & & B & $x$ & $x$ & $x$ & $x$ & $x$ & $x$ & $x$ & \\
\hline & & $\mathrm{C}$ & $x$ & $x$ & $x$ & $x$ & $x$ & $x$ & $x$ & \\
\hline & \multirow{3}{*}{ Blood } & A & $x$ & $x$ & $x$ & $x$ & $x$ & & $x$ & $x$ \\
\hline & & $B$ & $x$ & $x$ & $x$ & $x$ & $x$ & $x$ & $x$ & $x$ \\
\hline & & $\mathrm{C}$ & $x$ & $x$ & $x$ & $x$ & $x$ & $x$ & $x$ & $x$ \\
\hline
\end{tabular}

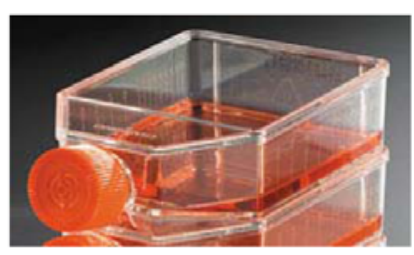

70-90\% Confluent cells: Replace media

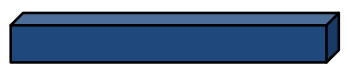

Place bar of sterile material directly on cells with sterilized tweezers

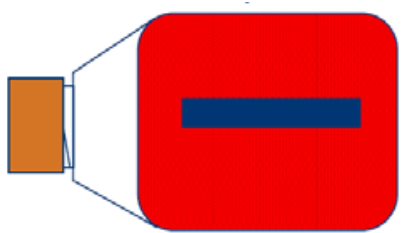

Return cells to $37^{\circ} \mathrm{C}$ in incubator for 24 hours

Figure 1: Illustration of material placement for direct contact cell cytotoxicity experiment. 
Table 2: Quantitative assessment scale for direct contact cytotoxicity assay interpretation, adapted from ISO 10993-5 (3).

\begin{tabular}{|c|c|}
\hline Cytotoxicity Scale & Interpretation \\
\hline 0 & Non-cytotoxic \\
\hline 1 & Mildly cytotoxic \\
\hline 2 & Moderately cytotoxic \\
\hline 3 & Severely cytotoxic \\
\hline
\end{tabular}
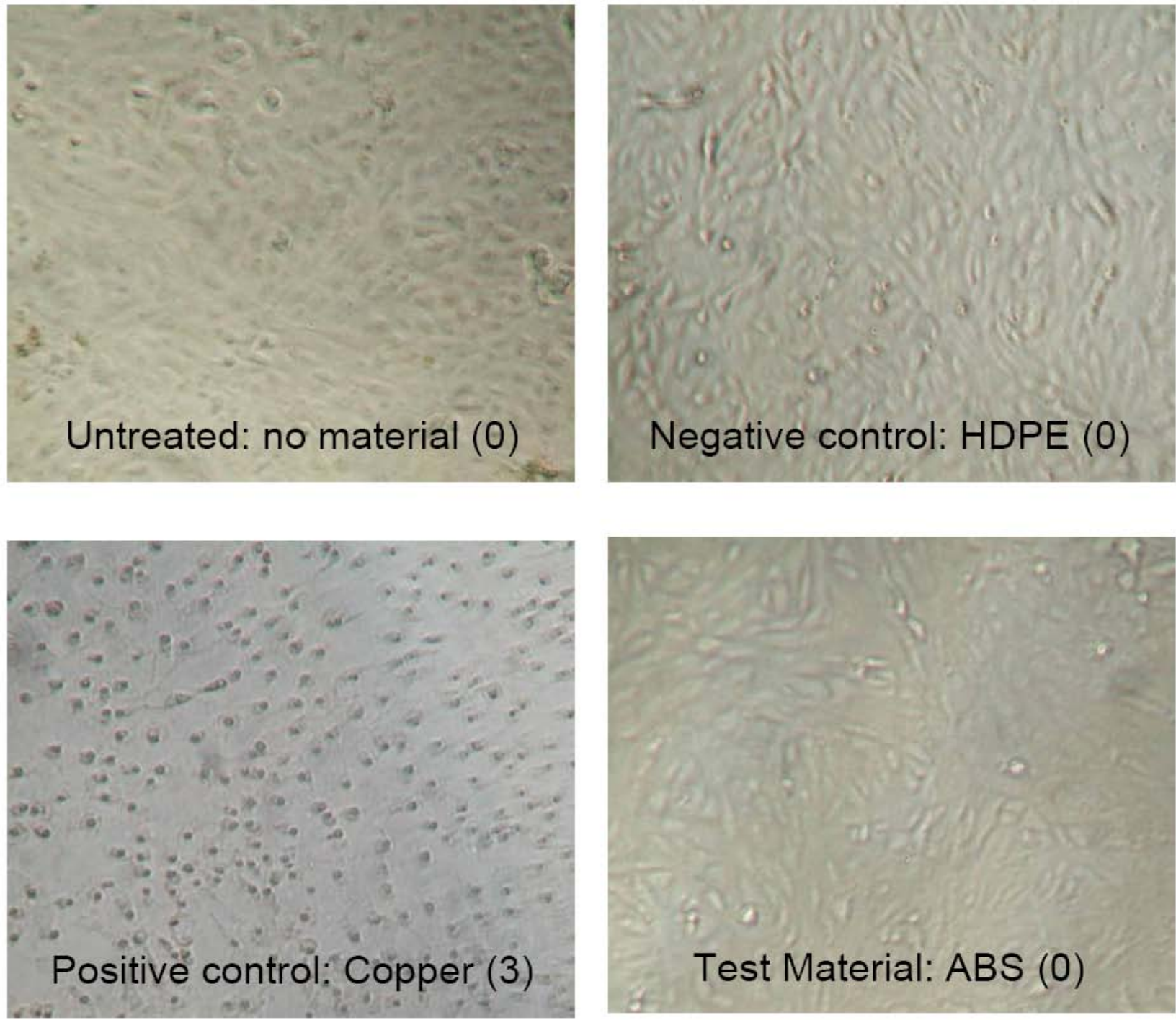

Figure 2: Example results from a direct contact cell cytotoxicity assay. Micrographs show representative cells in each culture flask far from the material specimen after 24 hours of incubation with the indicated material. Numbers in parentheses are scores based on the cytotoxicity scale in Table 2. All images were taken at the same magnification. 
Adapting Standards for Classroom Use

The main feature in our protocol that varied from the standards is that we used $50 \mathrm{ml}$ flasks instead of the recommended Petri dishes or well plates to minimize the risk of spilling and contamination of the incubator. The flasks have a culture area of $25 \mathrm{~cm}^{2}$, and we used materials with a cross-sectional area of $2.42 \mathrm{~cm}^{2}$ (rectangular specimens $38.1 \mathrm{~mm}$ x $6.4 \mathrm{~mm}$ that could easily fit through the flask opening), covering approximately $10 \%$ of the surface area (3). The rectangles were machined from large sheets of $1.6 \mathrm{~mm}$ thick polymer sheets and $0.8 \mathrm{~mm}$ thick copper sheet (McMaster-Carr), and were sterilized with alcohol before use in the cell culture experiments. Alcohol-sterilized tweezers were used to place the samples into the flasks, and a different pair of tweezers was used for each material to prevent cross-contamination.

We have used a variety of different cells in this experiment in different years, depending on the cells types that were being used by the biology labs at the time. These include HeLa and VERO cells. Independent of cell type, cells were cultured in Dulbecco's Modification of Eagle's Medium (DMEM, Sigma Aldridge) with 10\% calf bovine serum (Gibco/Invitrogen). We also had students take pictures of flasks to include in their cell culture report appendix using a camera attached to microscope. Since there was only one camera and two microscopes available, the 24 hour post-material placement target time was flexed to allow groups to sign up for different halfhour increments. To facilitate scheduling times as close to 24 hours as possible, all team members were not required to attend the observation session.

Cell culture lab activities were performed in groups of three. The specific activities performed in each of the five lab sessions are summarized below:

1. Introduction to the Lab: lab tour, introduction to sterile technique and cell counting; we demonstrate sterile technique and cell splitting simultaneously, having the class watch as we split one flask of cells into enough flasks for one flask for each team in the next lab session; these cells are then used in lab step 2: cell splitting and passage.

2. Cell Splitting and Passage: each team receives one flask of cells that they split and pass into three new flasks to use the next session; each team receives their own bottle of media and trypsin.

3. Cytotoxicity Assay I: Cell Splitting and Passage: pool three flasks from previous cell pass; split and pass cells into $\geq 12$ flasks for cell cytotoxicity assay to be performed in the next session (seed cells appropriately to have nearly confluent flasks at the next lab session; the number of cells to seed will vary depending on the number of days between lab session and the type of cell and size of flask being used).

4. Cytotoxicity Assay II: Begin Cytotoxicity Assay: when cells are $~ 70-90 \%$ confluent add materials to 12 flasks (Figure 1) - 3x no material (untreated controls), 3x negative control (high-density polyethylene), 3x positive control (copper), 3x of test material (polypropylene, acrylic, Delrin ${ }^{\mathrm{TM}}$, acrylonitrile butadiene styrene (ABS), polyvinyl chloride, and polycarbonate). NOTE: In our study, test materials are the same materials used in the manufacturing unit; but you can choose a range of materials depending on whether you want to demonstrate cytotoxic or non-cytotoxic responses. 
5. Cytotoxicity Assay III (24 Hours After Cytotoxicity Assay II): Evaluation: each team scores the cytotoxic response of the materials in each flask according to the qualitative scale outlined in ISO 10993-5 (Table 2); teams document each flask and take pictures of cells in flasks near to and far from material sample (Figure 2); evaluation summarized in lab report

In our course, the above laboratory sequence was completed in two weeks, although additional supplemental activities can be added to the cell-culturing unit. The first four lab activities were completed in 1.5 hour scheduled lab sessions on Tuesdays and Thursdays. The last part, observation of the flasks, was performed by students independently on a Friday outside of the regularly scheduled lab periods (and typically required less than one hour per group). Note that the introductory topics, lab activities 1 and 2, could be performed the same week as the lecture if you have enough class time to have both lecture and lab the same week. Alternatively, lab activities 1 and 2 could be performed the same day if you have a 3 or 4 hour lab session rather than a 1-2 hour lab session. Based on the ISO and ASTM standards, evaluation of the cell cytotoxicity results should take place approximately 24 hours after materials are placed on the cells. However, we allowed some flexibility in that time for scheduling purposes, with no detrimental effect on the outcome.

\section{Resources}

Cell culturing is not an inexpensive laboratory experience based on either start-up or consumable costs. Capital equipment required to maintain cell lines includes an incubator, one or more laminar flow hoods, a refrigerator and freezer for media and cell supply storage, and microscopes, which can total over $\$ 10,000$. To help control costs and take advantage of existing laboratory infrastructure, our lab module is conducted using facilities owned and maintained by the biology department, eliminating the need for capital equipment investment and limiting the unit's cost to consumables only. For each group performing cell culturing, approximately \$250$\$ 300$ of consumables are used over the course of the unit. A tabulated list of the most commonly used laboratory supplies is given in Table 3.

Table 3: Itemized list of supplies per group for the core cell culturing unit. These estimates are based on average consumption per group, including waste materials.

\begin{tabular}{|l|c|c|}
\hline \multicolumn{1}{|c|}{ Description } & $\begin{array}{c}\text { Quantity Used } \\
\text { (per lab group) }\end{array}$ & $\begin{array}{c}\text { Estimated Cost } \\
\text { (per lab group) }\end{array}$ \\
\hline Bovine serum (50 mL) & $1 \mathrm{x}$ & $\$ 54.00$ \\
\hline DMEM (500 mL) & $1 \mathrm{x}$ & $\$ 100.00$ \\
\hline $0.25 \%$ Trypsin-EDTA (100mL) & $1 \mathrm{x}$ & $\$ 12.00$ \\
\hline Plug cap flasks (50-70 mL) & $20 \mathrm{x}$ & $\$ 27.50$ \\
\hline Pipettes (25 mL) & $2 \mathrm{x}$ & $\$ 2.50$ \\
\hline Pipettes (10 mL) & $60 \mathrm{x}$ & $\$ 27.50$ \\
\hline Pipettes (5 mL) & $25 \mathrm{x}$ & $\$ 12.50$ \\
\hline Pipettes (1 mL) & $20 \mathrm{x}$ & $\$ 5.00$ \\
\hline Eppendorf tubes & $12 \mathrm{x}$ & $\$ 2.50$ \\
\hline Hemocytometer & $6 \mathrm{x}$ & $\$ 12.50$ \\
\hline & TOTAL & $\mathbf{2 6 1 . 0 0}$ \\
\hline
\end{tabular}


As the majority of the cost of the unit comes from serum and cell medium, additional add-ons to the unit (as described in the Supplemental Activities section below) come at a nominal investment. Typically, the core module consumes less than half of the DMEM supplied to each group. To reduce costs, the media could be shared between multiple groups. As a general rule, each additional passage or new flask of cells comes at a material cost of approximately $\$ 3.00$ $\$ 4.00$.

It should be noted that test specimens for the cytotoxicity assay (copper, high-density polyethylene, polypropylene, acrylic, Delrin ${ }^{\mathrm{TM}}$, acrylonitrile butadiene styrene (ABS), polyvinyl chloride, and polycarbonate) were manufactured in bulk from raw 12" by 12" sheets the first year of the course and provide enough raw material to run the unit for a minimum of 25 total groups. The initial cost of these materials was approximately $\$ 60$.

This cell culture-based biocompatibility module can be shortened if lab time or resources are limited. If the goal of the unit is biocompatibility and not cell culture experience, the cytotoxicity assay could be performed in only 2.5 lab hours spread over two days. Flasks of cells could be prepared by the instructor or TA ahead of time, and the students could be involved only in activities 4 and 5 of the lab experiment. If lab time is not an option, the students could be involved only in activity 5, which could be completed in a classroom setting if microscopes are available. This would also reduce the resources required, since only one set of controls would be needed.

\section{Assignments}

Two assignments were developed as deliverables and used in assessment of student learning outcomes. These were:

1. A biocompatibility homework assignment

2. A cell cytotoxicity lab report

The homework assignment includes questions pertaining to the lecture, such as:

a. One response to implantation of a foreign material that may be considered biocompatible for some applications is the formation of a stable fibrous capsule. For each of the following medical implants, state whether the result of a fibrous capsule would or would not be considered a biocompatible outcome and briefly explain why.

i. An implantable artificial pancreas. Assume the device is made up of a semipermeable membrane enclosing pancreatic islet cells, and that the encapsulated cells respond to glucose levels in the surrounding body fluids and secrete insulin as needed.

ii. A silicone breast implant that serves a primarily aesthetic function.

b. List three properties of an implant that may contribute to the development of chronic inflammation or a foreign body response, and briefly explain how each may contribute to prolonging the inflammatory response.

c. For each of the following medical devices, state the category in Table 1 that it would fall under (by specifying body contact type and contact duration). Based on this assessment, list the biological evaluations that might need to be performed on this device to receive FDA approval. Specify whether each test is recommended to be 
performed in an initial evaluation or a supplemental evaluation, and whether each is required by the ISO standard (indicated by $\mathrm{X}$ in table) or an additional test recommended for consideration by the FDA (indicated by an $\mathrm{O}$ in the table).

i. The adhesive on a nicotine patch. (They go on your skin and time release a certain amount of nicotine into your system for almost 24 hours.)

ii. A vascular stent to be permanently implanted in an artery and keep the blood vessel open after the angioplasty balloon is removed.

The cell cytotoxicity report consists of a one-page summary of the methods, results and conclusions of the cytotoxicity study, similar to what might be drafted for an FDA report. The results and conclusions are expected to be supported by an appendix which includes representative pictures of the cells in each flask and detailed observational comments.

\section{Supplemental Activities}

This cell-culture based biocompatibility module can be readily expanded through incorporation of related supplemental activities. Suggestions for supplemental activities that can be incorporated into the unit are included below:

\section{Expanded Group and Individual Cell Culturing}

While the core cell culturing unit includes two rounds of cell passages as a lab group, it was observed that this sometimes led to unequal opportunity between group members to practice their hands-on sterile technique during cell passages. This was particularly an issue in cases where one group member was less adept at cell splitting and chose to play a supporting role for the group, resulting in limited experience working with the cells. For this reason, a one-week supplemental module was added to the course in fall 2011 that required each student to maintain their own cell line and complete cell passages independently for a one-week period.

During this one-week period (inserted between lab activities 2 and 3), students can perform individual cell counts on their own cell lines as well as build their experience with sterile technique and working with cells. Each student starts with one confluent flask of cells and splits that into multiple flasks using various split ratios. Students can be required to make observations about cell growth (estimating confluence) every 24-36 hours, and perform cell growth rate calculations between the time that they plated their initial flasks and the time that the new flasks reach near-confluence. Based on their experience, students can then plan and perform one final split that will leave them with a minimum of one fully confluent flask at the beginning of the next week, in preparation for lab activity 3 (Cytotoxicity Assay I).

\section{Training Videos}

Another supplementary module that can be used to ensure that students perfect their sterile technique and demonstrate their competence (as well as share tips and tricks) is to have each team produce a training video to demonstrate both the proper way to perform the technique and common pitfalls for a specific operation performed during cell splitting. While the list of topics for training videos is open-ended, some example videos topics are:

1. Good and bad sterile pipetting technique,

2. Using trypsin to get cells into suspension,

3. Performing cell splits with cells already in suspension, 
4. Counting cells using the hemocytometer (starting with cells already in suspension),

5. Overview of laminar flow hood and incubator use for cell-culturing,

6. Demonstration of effects of good and bad cell culturing technique.

Video projects can very easily consume vast amounts of time to produce. However, the growing popularity of video recording capability using digital cameras, cell phones, and tablet devices makes it easier for students to quickly capture video and get the video into post-processing software. Specifically for this assignment, students were encouraged to shoot, edit, and produce a video in no longer than a 2 hour session.

\section{Standards}

As mentioned above, the experimental protocol for the cell cytotoxicity assay was based on the following standards (1-5):

- $\quad$ ISO 10993-1: Biological evaluation of medical devices - Part 1: Evaluation and testing

- $\quad$ ASTM F748-04: Standard practice for selecting generic biological test methods for materials and devices

- $\quad$ ISO 10993-5: Biological evaluation of medical devices - Part 5: Tests for in vitro cytotoxicity

- ISO 10993-12: Biological evaluation of medical devices - Part 12: Sample preparation and reference materials

- $\quad$ ASTM F813-01: Standard practice for direct contact cell culture evaluation of materials for medical devices

To supplement the standards content of the unit, an introduction lecture to the use of standards in medical device development, based on an article by Kunst and Goldberg (12), was provided in fall 2011. Students were also given access to the standards to compare the protocol used in class to the information provided in the standards. We have observed that introducing students to the actual standards in this course leads to an increased awareness of standards, as indicated by more frequent referencing of standards in their senior design reports.

\section{Statistics}

Statistical methods can be reinforced by incorporation of supplemental activities that involve students in the design of the experiments and requiring statistical analysis of quantifiable results of the cell culture experiments.

Experimental design has been incorporated into the course in a number of different ways. In fall 2009, students were asked to identify potential sources of bias in the experiment and to propose methods to reduce bias. The class discussed the possibilities, and chose one method to implement when they performed the experiment. The method implemented by the class was to randomly assign materials to flasks. Specifically, if the cells were plated 1-12, instead of using flasks 1-3 for the untreated control, 4-6 for the negative control, 7-9 for the positive control, and 10-12 for the experimental material, three flasks were randomly assigned to each treatment group. In fall 2011, to reduce the time and resources for the cell cytotoxicity study, only one set of negative, positive, and untreated controls were created. Experimental design methods were implemented to determine how to make an unbiased set of controls when each group had been passing their own set of cells. The final plan developed by the students was to randomly assign flasks from the entire class to each group of materials (controls and treatments). 
For both of these approaches, one or two lectures were spent reviewing concepts of experimental design and having students work in groups to come up with ways to apply it to the cell cytotoxicity experiments. In a course that meets for both lecture and lab each week, this activity could easily be done in lecture concurrently with the second week of laboratory.

In addition to reinforcing experimental design concepts, statistical methods can be included in data analysis and the final report. To incorporate descriptive and inferential statistics into the cell culture analysis, quantitative measures are required. We had students use ImageJ software (a free image analysis software from $\mathrm{NIH}$ ) to analyze cell shape and size for each of the four treatment groups (untreated controls, positive controls, negative controls, and experimental materials). Students were asked to trace 10 cells from each flask, and used the software to compute cell shape and area. This data was then used to determine whether significant differences were observed between any of the four treatment groups. Students had to perform an ANOVA with post-hoc Bonferroni or Tukey HSD tests to identify differences between groups. If their material had a biocompatible (non-cytotoxic) response, they should have found that only the positive control (copper) had significantly different cell shape from the other three groups (because a cytotoxic material causes the cells to ball up, while under the other treatments the cells remain spread on the flask surface). Cell size was not always significantly different, even for the positive control.

Alternative quantitative analysis methods could also be incorporated into this unit. For example, cell counting, staining, or metabolic assays could be taught and utilized during evaluation of cytotoxicity results.

The methods for inferential analysis were reviewed in class (in one or two lectures), and the image analysis and statistical analysis were included as sections of the cell cytotoxicity report.

\section{Bioethics}

Although this has not been a major focus of our course, the cell culturing unit, particularly with the use of HeLa cells offers a unique opportunity to initiate a course-wide dialog into the topic of bioethics. A recent New York Times bestselling book, "The Immortal Life of Henrietta Lacks" by Rebecca Skloot (13), documents the origins of the HeLa cells and traces the origins of some modern day ethical standards in the medical field back to the 1950's when the field of cell culturing was only beginning.

The story and origins of HeLa cells provide a unique backdrop to modern day concepts of the Health Insurance Portability and Accountability Act (HIPAA), varying standards of medical care, and the discussion of medical research and profitability. Student interest in the history and ethics brought up by the contextual background of HeLa cells has been recalled by students in the ethics portion of the senior design course and could be expanded as part of a full unit on bioethics.

This ethical discussion required only one class period. 


\section{ABET Assessment ${ }^{1}$}

The core module was designed to address the ABET Bioengineering Program Criteria (7):

"The program must demonstrate that graduates have... the ability to make measurements on and interpret data from living systems, addressing the problems associated with the interaction between living and non-living materials and systems."

The two assignments, along with student participation in lab activities, were used to assess the following ABET performance criteria:

1. Define biocompatibility and interpret whether a particular response of the body to a medical device would be considered biocompatible.

2. Identify the appropriate ISO 10993-compatible biocompatibility tests that are recommended for a particular medical application or device.

3. Perform an in vitro cytotoxicity assay and interpret the results.

These criteria were evaluated on a 4-point scale, with 4 = Exemplary, 3 = Accomplished, $2=$ Developing, $1=$ Beginning, and $0=$ Failure. A summary of ABET performance criteria scores from direct assessment from years 2008 through 2011 is presented in Table 4.

Table 4: Sample performance criteria that address the interaction between living and non-living materials and systems. Direct assessment for performance criteria \#1 was not conducted as part of this course in 2010-2011.

\begin{tabular}{|l|c|c|c|c|}
\hline \multicolumn{1}{|c|}{ Performance Criteria } & $\mathbf{2 0 0 8}$ & $\mathbf{2 0 0 9}$ & $\mathbf{2 0 1 0}$ & $\mathbf{2 0 1 1}$ \\
\hline $\begin{array}{l}\text { Define and apply } \\
\text { biocompatibility definition }\end{array}$ & 3.12 & 3.33 & -- & 3.40 \\
\hline $\begin{array}{l}\text { 2. } \\
\text { Identify ISO 10993-1 } \\
\text { biocompatibility tests }\end{array}$ & 3.00 & 3.08 & 3.00 & 3.60 \\
\hline $\begin{array}{l}\text { 3. } \\
\text { Perform and interpret } \\
\text { results of cytotoxicity assay }\end{array}$ & 4.00 & 3.67 & 3.20 & \\
\hline
\end{tabular}

Some of the core and supplemental units can also be mapped to ABET criteria 3 (7). For example, the use of standards in identifying appropriate biocompatibility tests to perform can be used to assess 3c (an ability to design a system, component, or process to meet desired needs) or $3 \mathrm{j}$ (a knowledge of contemporary issues). The incorporation of statistical analysis into the cell culture data analysis can similarly be used to assess 3a (an ability to apply knowledge of mathematics, science, and engineering). Both the experimental design and inferential statistics components can also be used to assess $3 \mathrm{~b}$ (an ability to design and conduct experiments, as well as analyze and interpret data). The core module can also be readily mapped to 3b.

\section{Student Assessment ${ }^{1}$}

As mentioned in the introduction, student comments regarding the cell culture unit of this course greatly improved after implementation of the cell cytotoxicity assay. When the cell culture unit consisted of growth curve analysis, there were few positive comments and numerous negative comments on student course evaluations regarding the cell culture unit, largely relating to too much time spent in lab. After incorporation of the cell cytotoxicity unit, student comments shifted drastically. In the first offering, in 2008, when asked what they liked about the course,

\footnotetext{
${ }^{1}$ ABET and student assessment data are provided in compliance with Bucknell University’s Institutional Review Board (IRB).
} 
$12 / 16$ students commented that they liked the cell culture experience they got in the course. Some sample comments include:

"I liked doing the cell culture experiment/cytotoxicity assay because it's very pertinent to the industry. I also liked the unit on biocompatibility."

"Applying the stats and biocompatibility sections to the cell culturing makes them more relevant."

"I liked learning the cell culturing techniques as I think they will be helpful for biomedical engineering in the future. I think that the lab experiences were very helpful."

Also of note, the students appreciate the hands-on aspect of this unit (as well as others in the course) and have consistently scored the hands-on component of the course as valuable to the course. Unfortunately, relevant quantitative student assessment of the cell culture unit alone is limited due to the combined nature of the course (Table 5).

Table 5: Results from quantitative course evaluation questions from multiple offerings of the course. The first two questions in the table refer to the full course, including both the fabrication and cell culture units. The last two questions were the results of a supplemental evaluation offered in 2009. These criteria were evaluated on a 5-point likert scale, with 5 = Agree strongly, $3=$ Neutral, 1 = Disagree strongly.

\begin{tabular}{|c|c|c|c|c|}
\hline Evaluation Question & $\begin{array}{c}2008 \\
(n=17)\end{array}$ & $\begin{array}{c}2009 \\
(n=12)\end{array}$ & $\begin{array}{c}2010 \\
(n=15)\end{array}$ & $\begin{array}{c}2011 \\
(n=12)\end{array}$ \\
\hline $\begin{array}{l}\text { 1. Hands-on projects valuable } \\
\text { part of course }\end{array}$ & 4.37 & 4.08 & 4.80 & 4.58 \\
\hline $\begin{array}{l}\text { 2. Valuable in developing } \\
\text { new skills }\end{array}$ & 4.00 & 4.00 & 4.80 & 4.83 \\
\hline $\begin{array}{l}\text { 3. Gaining cell culture } \\
\text { experience was a valuable } \\
\text { part of this course }\end{array}$ & N/A & 4.42 & N/A & N/A \\
\hline $\begin{array}{l}\text { 4. Performing the cell } \\
\text { cytotoxicity experiment } \\
\text { was a valuable part of this } \\
\text { course }\end{array}$ & N/A & 4.25 & N/A & N/A \\
\hline
\end{tabular}

\section{Faculty Observations}

The faculty have observed two broader impacts of this unit within our design sequence. First, the cytotoxicity assay directly ties the cell culturing unit to the fabrication unit which occurs later in the same course. The students have demonstrated a greater appreciation for the additional complexities of material selection in biomedical applications because of their background in biocompatibility and cytotoxicity testing experience. Second, we have noted an increase in student use of standards in the senior capstone projects since this unit has been established. Most students demonstrate a better understanding and awareness of standards and are able to identify standards that are relevant to their particular design project. While a fair number of teams focus on ISO 10993 standards due to their familiarity with biocompatibility, teams also identify other areas of the project where standards may apply including material selection, feasibility and validation tests, and safety standards. 


\section{Discussion and Conclusions}

The cell culture-based biocompatibility unit described in this paper can be readily incorporated into a variety of courses, including material science or a dedicated cell culture course. Although the core unit as described is a combination of lecture and lab material that requires two weeks to complete, variations allow for the unit to be as short as one class period by using the cell cytotoxicity assay as a demonstration (with the cell culture work performed ahead of time by a TA or instructor) or as long as six weeks by incorporating numerous supplemental topics (such as statistics and ethics) into the lecture. In our course, we have found that an ideal cell culturing unit runs approximately four and a half total weeks, with time devoted to classroom lectures on biocompatibility and standards, familiarization with the cell culturing lab and equipment, students running an independent cell line for a week, plus the cell cytotoxicity assay described previously, followed by a cytotoxicity report and biocompatibility assignment.

This course has been taught to classes of 15-18 students working in teams of three students. Scaling the unit to larger classes may lead to some financial and space challenges. The cost for supplies for the core unit was approximately $\$ 250 /$ team. This includes disposable supplies such as flasks, pipettes, media, and trypsin. Cells were donated by the biology department, and hence were not included in the costs. With five to six teams, and performing only group culturing, the use of only one incubator was required. Five hoods were available, three large enough for two groups to use at once, providing sufficient hood access for all teams. The only bottleneck was the use of a microscope and camera for cell observation during the final hour of lab, which was addressed by having students sign up for 30-minute time slots ahead of time. Some options for scaling up to larger class sizes include: increasing group sizes, eliminating the extra cell splitting (lab session 2) step, and performing the experiment as a class (instead of as groups) so that only one set of controls is required.

In conclusion, this self-contained module provides biomedical engineering students with relevant cell culture experience in addition to exposure to the interactions between living and non-living materials. The success of this unit is supported by high assessment scores (scores $\geq 3$ out of 4 for related performance criteria and $\geq 4$ out of 5 for course evaluation questions) and student comments. This nominally three-week unit can be tailored for incorporation into a variety of engineering, materials science, or cell-culture courses.

\section{References}

1. International Organization for Standardization (2009) ISO-10993 Biological Evaluation of Medical Devices - Part 1: Evaluation and Testing Within a Risk Management Process.

2. American Society for Testing and Materials International (2004) ASTM F748: Standard Practice for Selecting Generic Biological Test Methods for Materials and Devices

3. International Organization for Standardization (2009) ISO-10993 Biological Evaluation of Medical Devices - Part 5: Tests for In Vitro Cytotoxicity.

4. International Organization for Standardization (2009) ISO-10993 Biological Evaluation of Medical Devices - Part 12: Sample Preparation and Reference Materials.

5. American Society for Testing and Materials International (2004) ASTM F813-01: Standard Practice for Direct Contact Cell Culture Evaluation of Materials for Medical Devices 
6. US Food and Drug Administration. Use of International Standard ISO-10993, "Biological Evaluation of Medical Devices Part 1: Evaluation and Testing”

$<<$ http://www.fda.gov/MedicalDevices/DeviceRegulationandGuidance/GuidanceDocuments/ ucm080742.htm>> Last accessed January 11, 2012.

7. ABET. Criteria for Accrediting Engineering Programs, 2012-2013 << http://www.abet.org/engineering-criteria-2012-2013/>> Last accessed January 11, 2012.

8. Hench, LL and Jones, JR (2005) Biomaterials, Artificial Organs and Tissue Engineering. CRC Press, London.

9. Ratner, BD, et al. (2004) Biomaterials Science: An Introduction to Materials in Medicine. Elsevier Academic Press, London.

10. Temenoff, JS, and Mikos, AG (2008) Biomaterials: The Intersection of Biology and Materials Science. Pearson Prentice Hall, London.

11. Medical Device and Diagnostic Industry. A Practical Guide to ISO 10993: Part 1Introduction to the Standards $<<$ http://www.mddionline.com/article/practical-guide-iso10993-part-1151introduction-standards >> Last accessed January 11, 2012.

12. Kunst, BS and Goldberg JR (2003). Standards Education in Senior Design Courses. IEEE Engineering in Medicine and Biology Magazine.

13. Skloot, R (2010). The Immortal Life of Henrietta Lacks. Crown Publishers, New York. 